\title{
Novel external field source by localization of electrons for improvement of solar cells
}

\author{
D. König, G. Ebest
}

Chair of Electronic Devices, Faculty of Electrical Engineering \& Information Technology, Technical University of Chemnitz, D-09107 Chemnitz, Germany_dirk.koenig@e-technik.tu-chemnitz.de

\begin{abstract}
For drift field generation IS structures with a fixed positive charge were developed in the 80's and employed on solar cells. While many papers were published about the positively charged IS structure there has been little interest in a negatively charged IS structure (I-S structure) [1]. In comparison to solar cells with back surface field (BSF) such structures could improve conversion efficiency more significantly. They also open the way to novel field effect supported solar cells on n-type silicon.

The paper represents results of the preparation and characterization of the $\mathrm{I}^{-} \mathrm{S}$ structure on Silicon ( $\mathrm{Si}$ ) consisting of a layer compound $\mathrm{AlF}_{3} \| \mathrm{SiO}_{2}$ on $\mathrm{Si}$, a discussion of the phenomena encountered and respective conclusions.
\end{abstract}

Keywords: fixed charges, field effect, surface passivation, electron localization

\section{Introduction}

The negatively charged IS structure (I ${ }^{-}$S structure) already described in $[2,4]$ is built up according to fig. 1.

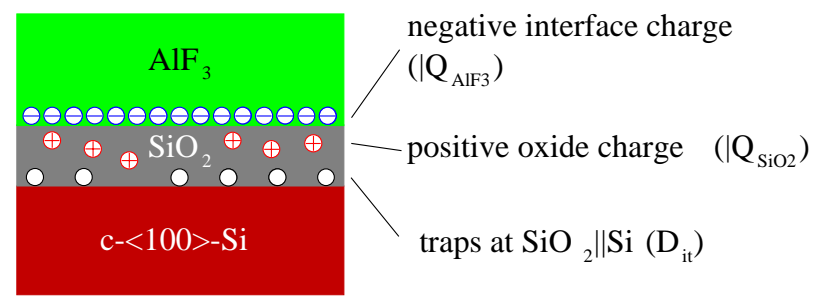

Fig. 1: I'S structure consisting of $\mathrm{AlF}_{3}$ deposited onto an oxidized Si wafer

As the most recent results are subject to this publication we refer to $[2,4,6]$ for further information.

\section{Applications}

The $\mathrm{I}^{-} \mathrm{S}$ structure [3] can be used for

I. passivating solar cell surfaces where electron injecting electrodes contact a p-type conduction layer (field induced by I'S structure or by doping) [4].

Advantages:

Minorities (free electrons) are accelerated away from surface, thereby decreasing surface recombination rate $\mathrm{R}_{\mathrm{s}}$; material degradation due to heavy doping (thermally inactive dopands, strained/broken bonds) is prevented. An additional external drift field source exists which improves charge carrier separation at significant charge transport (i. e. currents, e.g. at MPP) - useful especially for thin active layers $(\mathrm{d} \leq 100 \mu \mathrm{m})$.

II. a good anti reflection (AR) coating; $\mathrm{AlF}_{3}$ is transparent for $\lambda \geq 200 \mathrm{~nm}, \mathrm{n} \approx 1.37$ in $\lambda \in[400 ; 1200] \mathrm{nm}$. Advantages:

Optical gain at respective surface is increased; usage at bifacial solar cells. Applicable in compound with field effect passivation (analogous to $\mathrm{Si}_{3} \mathrm{~N}_{4} / \mathrm{SiO}_{2}$ layer compounds with fixed positive charges on $\mathrm{Si}$ )

III. preparing $\mathrm{p}$ inversion layer solar cells on $\mathrm{n}-\mathrm{Si}$ and preparing first solar cells completely governed by field effect [5] for the first time ever.

Advantages:

First $\mathrm{p}$ inversion layer solar cell, first solar cell completely governed by field effect $\rightarrow$ research, development of novel solar cell structures. No interstitial $\mathrm{BO}_{5}$ complexes representing effective recombination centres by using Phosphorous doped Si as a substrate.

\section{Sample preparation, technological aspects}

$4 "<100>$ Si wafers were oxidized by

- a conventional furnace process for growing silicon dioxide $\left(\mathrm{SiO}_{2}\right)$ of $\mathrm{d}_{\mathrm{SiO} 2}=90 \AA$.

- a rapid thermal oxidation process (RTO) for growing $\mathrm{SiO}_{2}$ of $\mathrm{d}_{\mathrm{SiO} 2}=32$ and $15 \AA$.

On the oxidized $\mathrm{Si}$ wafers an $\mathrm{AlF}_{3}$ layer was deposited with a thickness of $\mathrm{d}_{\mathrm{AlF} 3}=100,200,600$ and $3550 \AA$.

Concerning technology the only new process is the deposition of $\mathrm{AlF}_{3}$ onto an oxidized Si substrate. As Fluorine (F) is an aggressive chemical element it is advisable to include the deposition as the last process in order not to contaminate processing equipment unnecessarily. That does not represent any problem since the 
deposition temperature with $\mathrm{T}=250{ }^{\circ} \mathrm{C}$ is fairly low and the deposition time is $\mathrm{t}=20 \ldots 180$ s. Hence all surfaces, doping profiles and gettered dangling bonds stay intact. Moreover the thermal budget for depositing $\mathrm{AlF}_{3}$ of the desired thickness is about $2.7 \times 10^{4} \mathrm{Ks}$ and thus extremely low. It is roughly as much as needed for producing the ultrathin $\mathrm{SiO}_{2}$ layer of $1.5 \mathrm{~nm}$ by Rapid Thermal Oxidation (RTO).

\section{Characterization}

For estimating the effective fixed charge $\mid \mathrm{N}_{\mathrm{eff}}$ of the $\mathrm{I}^{-} \mathrm{S}$ structure mercury probe capacitance-voltage $(\mathrm{Hg}-\mathrm{C} / \mathrm{V})$ measurements were carried out with an SSM 495.

The effective fixed charge $\mid \mathrm{N}_{\text {eff }}$ consists of all fixed charges within the insulting layers (i.e. $\left.\left|\mathrm{Q}_{\mathrm{SiO} 2},\right| \mathrm{Q}_{\mathrm{AIF} 3}\right)$ which are normalized to the interface $(\|) \mathrm{SiO}_{2} \| \mathrm{Si}$ with respective relative dielectric constants $\varepsilon_{\text {rel }}$ and the distance from $\mathrm{SiO}_{2} \| \mathrm{Si}$. Fig. 2 shows the evolution of $\mid \mathrm{N}_{\text {eff }}$ with time of samples stored in ambient air at room temperature. The progress within the last 12 months [6] is considerable. Currently $I^{-} S$ structures with $\mid N_{\text {eff }}==-4 \times 10^{12} \mathrm{~cm}^{-2} \mathrm{can}$ be prepared.

The fixed charge of the respective insulation layer varies with layer thickness and conditions of preparation. With a fixed oxide charge of $\mid \mathrm{N}_{\mathrm{SiO} 2} \approx 2 \times 10^{11} \mathrm{~cm}^{-2}$ the respective fixed charge of the $\mathrm{AlF}_{3}$ is $\mid \mathrm{Q}_{\mathrm{AlF} 3}=-5 \ldots-$ $11 \times 10^{12} \mathrm{~cm}^{-2}$. $\mid \mathrm{Q}_{\mathrm{AlF} 3}$ occurs at $\mathrm{AlF}_{3} \| \mathrm{SiO}_{2}$ so that an increasing thickness of the $\mathrm{SiO}_{2}$ layer decreases its field impact and thereby $\mid \mathrm{N}_{\mathrm{eff}}$.

For the localization of electrons in deep potential wells an $\mathrm{F}$ deficiency at $\mathrm{AlF}_{3} \| \mathrm{SiO}_{2}$ is essential. According to measurements of the compositional parts of Aluminium (Al) and $\mathrm{F}$ within the $\mathrm{AlF}_{3}$ there exists a significant $\mathrm{F}$ deficiency as can be seen in Fig. 3. For measurement inclined-angle RBS was used.

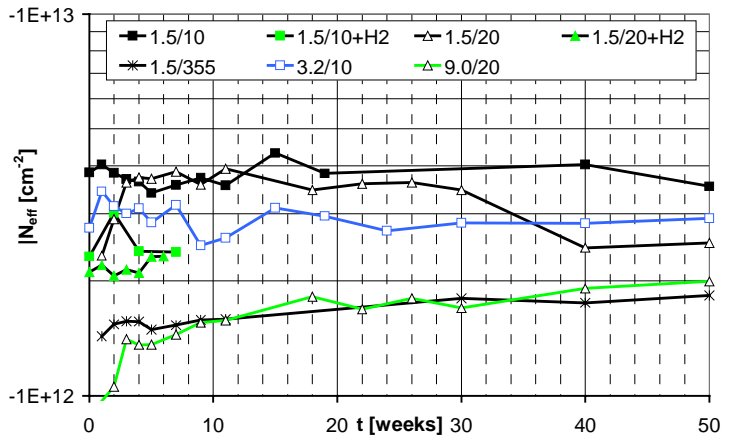

Fig.2: $\mid \mathrm{N}_{\mathrm{eff}}$ as $\mathrm{f}(\mathrm{t})$ for different samples, stored in air at room temperature

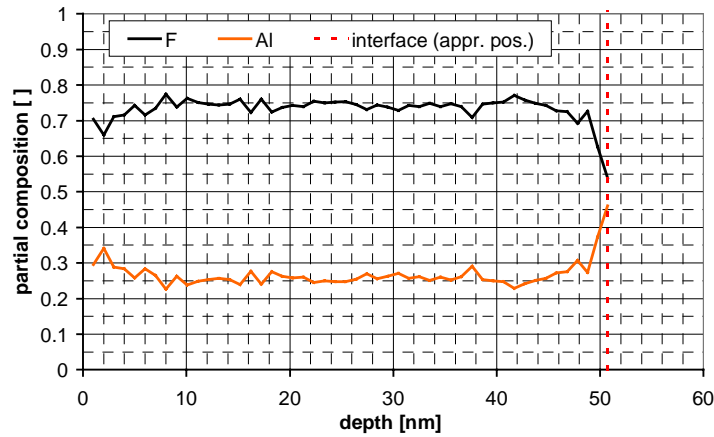

Fig. 3: parts of $\mathrm{Al}$ and $\mathrm{F}$ on $\mathrm{AlF}_{3}$ depending on layer depth; $\mathrm{AlF}_{3}$ was deposited on oxidized $\mathrm{Si}$.

When characterizing samples by $\mathrm{Hg}-\mathrm{C} / \mathrm{V}$ an annormal tilt of the $\mathrm{C} / \mathrm{V}$ curve was detected. This transient phenomenon gave a profound insight into the mechanism of electron localization as discussed below. Fig. 4 shows $\mathrm{C} / \mathrm{V}$ curves of both a normal sample and a sample being within the transient charge anomaly.

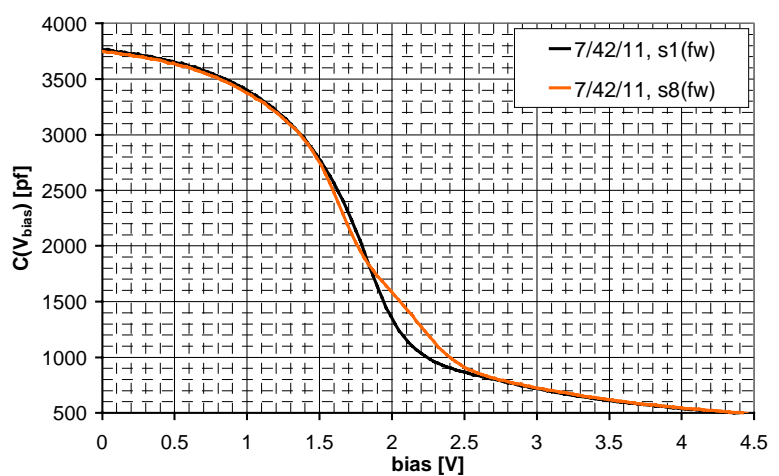

Fig. 4: C/V curves of a normal sample (s1) and of a transient charge anomaly (s8)

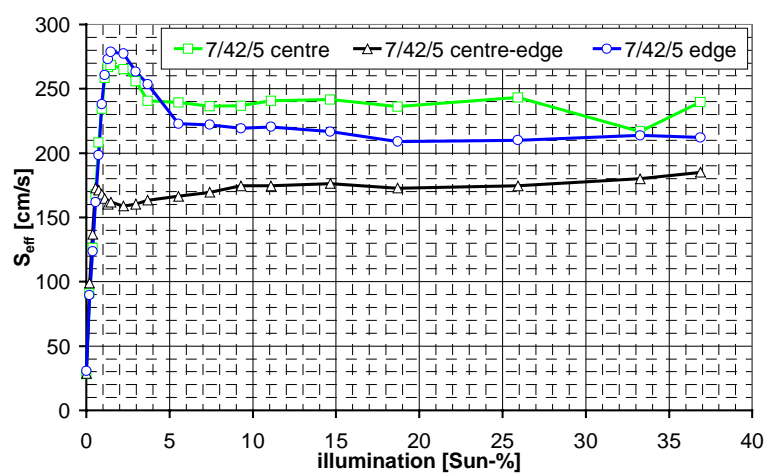

Fig. 5: $\mathrm{S}_{\text {eff }}$ of sample $7 / 42 / 5$ on different wafer positions

First measurements of the effective recombination velocity $S_{\text {eff }}$ by $\mu$ W-PCD at the ISFH showed that $S_{\text {eff }}$ varies from $170 \mathrm{cms}^{-1}$ to $520 \mathrm{cms}^{-1}$ depending on sample. Fig. 5 shows $S_{\text {eff }}$ depending on wafer position for sample $7 / 42 / 5\left(\mathrm{~d}_{\mathrm{SiO} 2}=15 \AA, \mathrm{d}_{\mathrm{AlF} 3}=200 \AA\right)$. Due to novelty of the $\mathrm{I}^{-} \mathrm{S}$ structure and the phenomena involved this value is quite promising. Values below $100 \mathrm{cms}^{-1}$ should be feasible by further optimization. By using n-Si as a substrate - as planned for prototypes $-S_{\text {eff }}$ should decrease even further because the negative band bending would be about four times as large as the positive band bending which occurs within $\mathrm{p}-\mathrm{Si}$. Then the massive displacement of majority carriers should enable the $I^{-} S$ structure to reach $S_{\text {eff }}$ values as low as already known from Siliconoxynitride $\left(\mathrm{SiO}_{\mathrm{x}} \mathrm{N}_{\mathrm{y}}\right)$ passivation layers of $\mathrm{n}$ inversion layer MIS solar cells. 
The impact of solar radiation on the $\mathrm{I}^{-} \mathrm{S}$ structure was investigated for detecting any degradation of $\mid \mathrm{N}_{\text {eff }}$. In contrast to common solar cell surface structures $\mid \mathrm{N}_{\mathrm{eff}}$ increased by $38 \%$ due to illumination (solar spectrum, $\mathrm{AM}$ $1.5,1 \mathrm{Sun})$, levelling off after $8 \mathrm{~h}$ irradiation time at $-4.85 \times 10^{12} \mathrm{~cm}^{-2}$.

\section{Interpretation of measurement results - brief model description of the IS structure}

As mentioned above $\mathrm{F}$ vacancies are essential for localizing electrons. Within proximity of $\mathrm{AlF}_{3} \| \mathrm{SiO}_{2}$ the substoichiomety of $\mathrm{F}$ changes the composition of $\mathrm{AlF}_{3}$ thus that there is $\mathrm{AlF}_{\mathrm{x}}, \mathrm{x} \approx 2.4$ instead of $\mathrm{AlF}_{3}$. That generates a density of $\mathrm{F}$ vacancies of $\mid \mathrm{N}_{\mathrm{F}-\mathrm{Vac}}=5 \times 10^{14} \mathrm{~cm}^{-2}$. Due to charge equilibrium within $\mathrm{AlF}_{3}$ the ionization of $\mathrm{F}$ atoms increases; their are charged as $\mathrm{F}^{-0.9}$ instead of $\mathrm{F}^{-0.75}$. The decrease in ionization of $\mathrm{Al}$ atoms is marginal.

Within $\mathrm{AlF}_{3}$ charges are balanced initially. Therefore the electrons represent an additional charge within $\mathrm{AlF}_{3}$. With $\mid \mathrm{N}_{\mathrm{F}-\mathrm{Vac}}$ and $\mid \mathrm{N}_{\mathrm{AlF} 3}=-5 \times 10^{12} \mathrm{~cm}^{-2}$ calculated from measurement results it is obvious that about every $100^{\text {th }} \mathrm{F}$ vacancy is occupied with an electron.

$\mathrm{AlF}_{3}$ is an insulator; there are no free charge carriers. Therefore the electrons have to penetrate $\mathrm{AlF}_{3}$ from $\mathrm{Si}$ by tunneling through the thin $\mathrm{SiO}_{2}$ layer. The energy which is necessary for electron tunneling towards the $\mathrm{F}$ vacancies is provided by the Coulomb force of $\mathrm{F}$ vacancies, promoted by a giant potential step of about $4 \mathrm{eV}$ from the Fermi level within $\mathrm{Si}$ to these $\mathrm{F}$ vacancies which are just above the valence band edge of $\mathrm{AlF}_{3}$. That can be seen in fig. 2 since the negative charge increases with storage time. The giant potential step is also responsible for the localization of electrons within $\mathrm{AlF}_{3}$; its $4 \mathrm{eV}$ in compound with the $\mathrm{SiO}_{2}$ layer prevents electrons from tunneling back into Si.

In section 3 a charge anomaly causing an additional twist of the $\mathrm{C} / \mathrm{V}$ curve was mentioned. The relatively low occupation probability of $\mathrm{F}$ vacancies indicates that their majority is situated are above the Fermi level. The charge anomaly strongly suggests that the occupied F vacancies can be classified in two different subbands. While the lower one fixes electrons into deep potential wells the Coulomb force of the upper one is weak enough to allow for limited delocalization within $\mathrm{AlF}_{3}$ (hopping conduction, [7]) at strong bias fields as long as this subband is not fully occupied yet. That phenomenon occurs within the first couple of weeks from preparation. Its duration depends on the tunneling rate of electrons as it estimates the charge of $F$ vacancies as a function of time.

Fig. 7 shows the $1^{\text {st }}$ derivatives $\partial \mathrm{C} / \partial \mathrm{V}$ of a normal $\mathrm{C} / \mathrm{V}$ curve and one with a charge anomaly. By detailed energetic band reconstruction based on $\mathrm{Hg}-\mathrm{C} / \mathrm{V}$ results and respective material parameters [8] an energy subband with a charge density of $-1 \times 10^{11} \mathrm{~cm}^{-2}$ was estimated. It is increasingly occupied during the charging of the $\mathrm{I}^{-} \mathrm{S}$ structure. On the energy scale it is situated $0.85 \mathrm{eV}$ above $\mathrm{E}_{\mathrm{V}}\left(\mathrm{AlF}_{3}\right)$; it is the type II vacancy in fig. 6 . The charge forming the vast majority of $\mid \mathrm{N}_{\text {eff }}$ is situated maximally $0.38 \mathrm{eV}$ above $\mathrm{E}_{\mathrm{V}}\left(\mathrm{AlF}_{3}\right)$; it is the type III vacancy in fig. 6. The vacancy type I consists of the unoccupied $\mathrm{F}$ vacancies. On the energy scale it is situated at least several $\mathrm{kT}$ above $\mathrm{E}_{\mathrm{F}}\left(\mathrm{AlF}_{3}\right)$. The introduction of a thermodynamical tuning of interatomic distances by modified deposition parameters can lead to an increased occupation probability of $F$ vacancies because the subband energy levels will drop with increasing interatomic distance [8]. Hence an increased fixed negative charge $\mid \mathrm{N}_{\text {eff }}$ is still feasible.

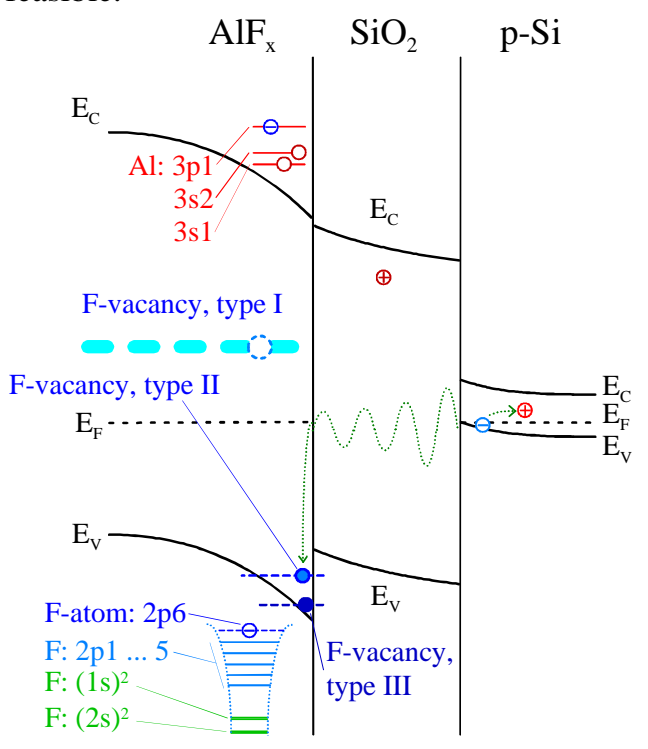

Fig. 6: energetic band model of the $\mathrm{I}^{-} \mathrm{S}$ structure

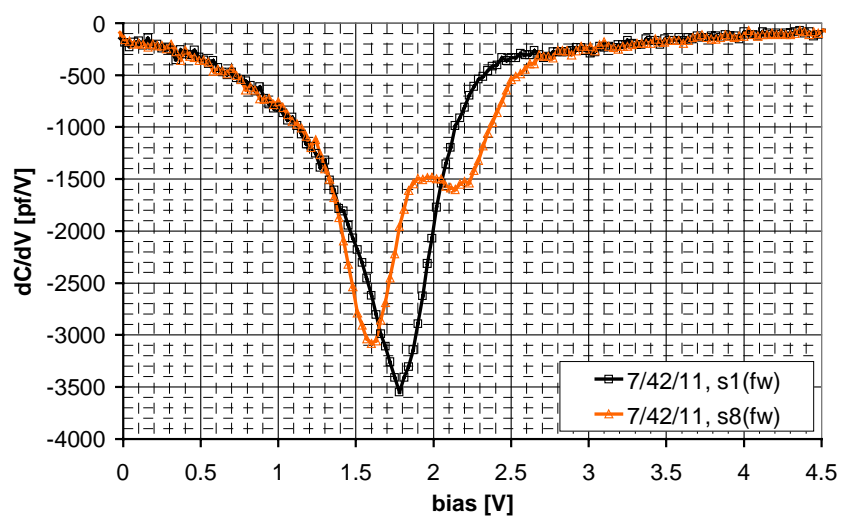

Fig. 7: $\partial \mathrm{C} / \partial \mathrm{V}$ of $\mathrm{C} / \mathrm{V}$ curves depicted in fig. 3; the anomaly leading to three turning points of the $\mathrm{C} / \mathrm{V}$ curve of sample 8 (s8) can be seen

The increase of $\mid \mathrm{N}_{\text {eff }}$ by exposing the $\mathrm{I}^{-} \mathrm{S}$ structure to solar irradiation (AM1.5, 1 Sun) of $38 \%$ is due to an increased density of electrons at $\mathrm{Si} \| \mathrm{SiO}_{2}$. These optically generated electrons got also the additional energy of the 
Si band gap so that their tunneling probability increases by several orders of magnitude, leading to an accelerated occupation of $\mathrm{F}$ vacancies. This phenomenon results in the paradox situation that the field effect performance of the $\mathrm{I}^{-} \mathrm{S}$ structure is getting better with solar irradiation.

It is worth notifying that the Eigenvalues of a one dimensional harmonic oscillator model with respective parameters (ionization energies, Madelung constants, interatomic distances, etc.) along the line $\mathrm{Al}-[\mathrm{F}]-\mathrm{Al}$ leads to two energy levels which can be occupied and of which one is situated very near $\mathrm{E}_{\mathrm{V}}\left(\mathrm{AlF}_{3}\right)$. The next Eigenvalue is already situated above $\mathrm{E}_{\mathrm{F}}\left(\mathrm{AlF}_{3}\right)$ and is thus cannot be occupied. For better understanding of the atomistic structure of $\mathrm{AlF}_{3}$ a small section of an $\mathrm{Al}_{6} \mathrm{~F}_{18}$ cluster is shown in Fig. 8.

A more detailed evaluation of measurement data including UPS, NEXAFS, and a comprehensive model evaluation $\mathrm{I}^{-} \mathrm{S}$ structure will be represented soon [9].

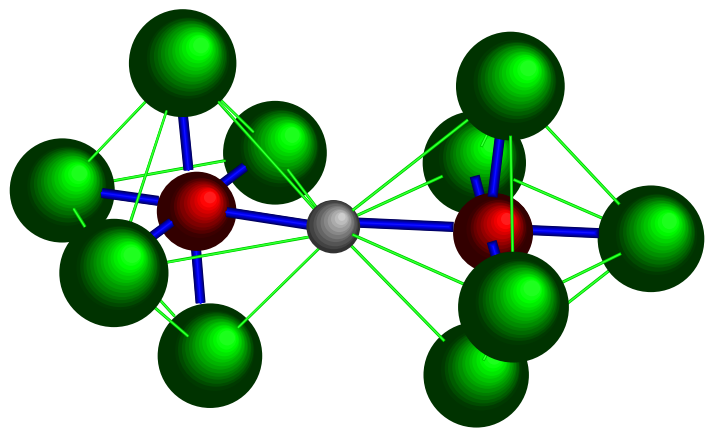

Fig. 8: two $\mathrm{AlF}_{6}$ octaeder with an electron located in an $\mathrm{F}$ vacancy (dark grey: $\mathrm{Al}$, grey: $\mathrm{F}$, bright grey: localized electron)

\section{Conclusions}

The $\mathrm{I}^{-} \mathrm{S}$ structure is able to induce a high density of localized electrons in the immediate vicinity to an Si substrate and is therefore a novel structure which can improve solar cell efficiency. Currently a nominal effective charge of $\mid N_{\text {eff }}=-4 \times 10^{12} \mathrm{~cm}^{-2}$ has been reached. In contrast to common solar cell structures the performance of the $\mathrm{I}^{-} \mathrm{S}$ structure increases with exposure to solar irradiation. After being exposed to 1 Sun, AM1.5 for $8 \mathrm{~h} \mid \mathrm{N}_{\text {eff }}$ increased by $38 \%$ to $\mid \mathrm{N}_{\text {eff }}=-4.85 \times 10^{12} \mathrm{~cm}^{-2}$. Both charges have been found to be stable in ambient air at room temperature.

$\mathrm{F}$ vacancies within $\mathrm{AlF}_{3}$ represent deep localization centres for electrons. Additional electrons tunneling from $\mathrm{Si}$ through $\mathrm{SiO}_{2}$ into $\mathrm{AlF}_{3}$ are driven by a giant potential step of $4 \mathrm{eV}$ and the attractive Coulomb force of unoccupied $\mathrm{F}$ vacancies when moving to $\mathrm{AlF}_{3}$. There are two subbands formed by occupied $\mathrm{F}$ vacancies. The type II vacancy localizes electrons slighly less so that electrons can move at strong bias fields by hopping conduction within $\mathrm{AlF}_{3}$ as long as these vacancies are not fully occupied yet.

\section{Acknowledgements}

Thanks to F. Schrempel, Institut für Festkörperphysik, FSU Jena, Germany, for inclined-angle RBS and S. Dauwe, ISFH, Germany, for $\mu \mathrm{W}$-PCD measurements.

The author is member of the $\mathrm{PhD}$ research project "Renewable Energies" of the German Research Society (DFG).

\section{References}

[1] K. Jäger, R. Hezel, A novel thin silsicon solar cell with $\mathrm{Al}_{2} \mathrm{O}_{3}$ as surface passivation, Proc. of the $18^{\text {th }}$ IEEE PVSC, Las Vegas, 1985, Proc. pp. 1752

[2] D. König, G. Ebest, The negatively charged insulator-semiconductor structure: concepts, technological considerations and applications, Sol. St. Electron. 44, 111 (2000)

[3] D. König, K. König, G. Ebest: Solarzellen-Oberfläche, German patent No. 10057 296.0, Nov. 2000

[4] D. König, M. Rennau, M. Henker, G. Ebest, Evidence of a high density of fixed negative charges in an insulation layer compound on silicon, Thin Solid Films 385, 126 (2001)

[5] D. König, G. Ebest, Novel thin film solar cell model with two antipolar MIS structures ,Solar Energy Mater. \& Solar Cells 56, 67 (1998)

[6] D. König, G. Ebest, Antipolar counterpart to the positively charged $\mathrm{SiO}_{x} \mathrm{~N}_{\mathrm{y}}$ layer for improvement of field effect solar cells, OC 9/5, $16^{\text {th }}$ Eur. PVSEC, 1-5 May 2000, Glasgow/UK, Proc. pp. 88

[7] B. Saboya, J. Chemin et al., Simultaneous observation of Rutherford scattering and ( $\alpha, \mathrm{x})$ reactions in $\mathrm{AlF}_{3}$ and $\mathrm{MgF}_{2}$ layers and correlation with their electrical properties, J. Phys. D: Appl. Phys. 8, 1008 (1975)

[8] D. König, PhD thesis, to be completed in 2002, TU Chemnitz, Germany

[9] D. König, R. Scholz, T. Kampen, D. R. T. Zahn, G. Ebest, in preparation 